\title{
LA MAQBARA DEL TOSSAL DE MANISES (ALICANTE)
}

\author{
THE MAQBARA OF THE TOSSAL DE MANISES (ALICANTE)
}

\author{
MANUEL OLCINA DOMÉNECH \\ EVA TENDERO PORRAS \\ ANTONIO GUILABERT MAS \\ MARQ, Alicante
}

\section{EL TOSSAL DE MANISES}

El yacimiento arqueológico del Tossal de Manises se localiza a 3.5 kilómetros al NE del núcleo urbano de Alicante, en el barrio de La Albufereta, sobre una colina de 38 m s.n.m., entre el Cabo de la Huerta y la Serra Grossa, dominando una pequeña bahía a resguardo de los vientos de tramontana y levante. Pero más que de la ocupación poblacional del solar de la ciudad iberoromana, habría que valorar e interpretar el área de $\mathrm{La}$ Albufereta como un nicho donde los lugares de hábitat, de carácter urbano o rural dependiendo de la época, oscilan a una y otra parte del humedal, evidenciando un poblamiento continuo en la zona. Los primeros restos de ocupación de este espacio se centran en la vertiente SO de La Albufereta, en los alrededores del Tossal de les Basses, donde se han sacado a la luz estructuras de momentos finales del Neolítico, así como otras fechadas en la Edad del Bronce, coetáneas al cercano poblado de la Serra Grossa (Rosser Limiñana y Fuentes Mascarell, 2007, 9-33). En este emplazamiento los materiales revelan la existencia de poblamiento ibérico, desde fecha antigua hasta el siglo III a. C., coincidente con la necrópolis de La Albufereta (Verdú Parra, 2005), momento en el que el hábitat basculará hacia el Tossal de Manises. Los materiales arqueológicos residuales nos hablan de una presencia en el cerro durante el ibérico pleno, hecho no reforzado con el hallazgo de niveles ni estructuras anteriores a la primera mitad del siglo III a. C., siendo en la etapa bárquida, último tercio de dicha centuria, cuando se produce la urbanización del enclave. La ciudad sucumbe a finales de la Segunda Guerra Púnica, derivando en un abandono de los terrenos que culmina, en época tardorrepublicana, con el asentamiento en la ciudad de nuevos contingentes de población. Dentro del período augusteo, se produce la municipalización del enclave con el nombre de Lucentum y regida por el derecho latino (Plinio, N.H., III, 3, 19-20). Este momento de auge de la ciudad se ve truncado en el último tercio del siglo I d. C., desembocando en su abandono definitivo en el período de la dinastía severa para dar paso a frecuentaciones de la zona en época bajoimperial/tardoantigua (Tendero Porras, Guilabert Mas y Olcina Doménech, 2007). En este período, en el área de La Albufereta, se localizan zonas de enterramiento de diferente rango y hallazgos arquitectónicos de carácter relevante. Finalmente será, durante los primeros momentos de dominación musulmana en la península, cuando se produzca una nueva ocupación del cerro del Tossal de Manises, de carácter exclusivamente funerario, no habiéndose documentado, a tenor de los trabajos arqueológicos, ni estructuras ni materiales asociados a un enclave de cultura islámica. Estamos pues, ante un área donde se nos ofrece una notable concentración demográfica entre los siglos VI y VII, continuidad poblacional ampliada por la existencia de la maqbara del Tossal de Manises, fechada entre los siglos VIII y X (Fig. 1), fechas corroboradas por los recientes análisis de $\mathrm{C}^{14}$ (Guilabert Mas, Tendero Porras y Olcina Doménech, 2007, 97) ${ }^{1}$.

\section{LA MAQBARA DEL TOSSAL DE MANISES}

\subsection{LAS EXCAVACIONES ANTIGUAS Y RECIENTES}

La combinación de los datos proporcionados en las excavaciones antiguas, cuyas primeras, parcas y difusas noticias se retrotraen a los años treinta del siglo XX, junto a las realizadas en sondeos puntuales durante la musealización del enclave (1994-1998) y

1. La ausencia de material en los niveles de la maqbara, planteó la necesidad de realizar un número mínimo de análisis radiocarbónicos, que proporcionaran un marco cronológico en el que incluir el uso del área como lugar de inhumación. La existencia de tres disposiciones diferentes dentro del conjunto, con leves variaciones de orientación, fue el factor determinante para la selección de las sepulturas sobre las que se realizaron los análisis (E9, E22 y E30), siendo además tres el número mínimo de muestras necesarias para evitar problemas de contaminación o marginalidad. 


\begin{tabular}{|c|c|c|c|c|c|}
\hline ENTERRAMIENTO & $\begin{array}{c}\text { CAL } 2 \text { SIGMA } \\
\text { (95\% PROBABILIDAD) }\end{array}$ & $\begin{array}{l}\text { CAL (M) } \\
2 \text { SIGMA }\end{array}$ & $\begin{array}{c}\text { CAL } 1 \text { SIGMA } \\
\text { (68\% PROBABILIDAD) }\end{array}$ & $\begin{array}{l}\text { CAL (M) } \\
1 \text { SIGMA }\end{array}$ & $\begin{array}{c}\text { FECHA } \\
\text { RADIOCARBÓNICA } \\
\text { CONVENCIONAL } \\
\end{array}$ \\
\hline $\begin{array}{c}9 \\
\text { (Beta-231883) }\end{array}$ & $\begin{array}{c}\text { BP } 1.290-1.140 \\
\text { AD } 660-\mathbf{8 1 0}\end{array}$ & $\begin{array}{l}\text { BP } 1.215 \\
\text { AD } 735\end{array}$ & $\begin{array}{l}\text { BP } 1.280-1.180 \\
\text { AD } 670-770\end{array}$ & $\begin{array}{l}\text { BP } 1.230 \\
\text { AD } 720\end{array}$ & $\begin{array}{l}\text { BP } 1.280 \pm 40 \\
\text { AD } 670 \pm 40\end{array}$ \\
\hline $\begin{array}{c}22 \\
\text { (Beta-231882) }\end{array}$ & $\begin{array}{l}\text { BP } 1.140-940 \\
\text { AD } 810-\mathbf{1 . 0 1 0}\end{array}$ & $\begin{array}{l}\text { BP } 1.040 \\
\text { AD } 910\end{array}$ & $\begin{array}{l}\text { BP } 1.060-970 \\
\text { AD } 890-980\end{array}$ & $\begin{array}{l}\text { BP } 1.015 \\
\text { AD } 935\end{array}$ & $\begin{array}{c}\text { BP } 1.120 \pm 40 \\
\text { AD } 830 \pm \mathbf{4 0}\end{array}$ \\
\hline $\begin{array}{c}30 \\
\text { (Beta-231881) }\end{array}$ & $\begin{array}{l}\text { BP } 1.270-1.060 \\
\text { AD } 680-890\end{array}$ & $\begin{array}{l}\text { BP } 1.165 \\
\text { AD } 785\end{array}$ & $\begin{array}{c}\text { BP } 1.230-1.210 \\
\text { BP } 1.180-1.070 \\
\text { AD } 720-740 \\
\text { AD } 770-880\end{array}$ & $\begin{array}{c}\text { BP } 1.220 \\
\text { BP } 1.125 \\
\text { AD } 730 \\
\text { AD } 825\end{array}$ & $\begin{array}{l}\text { BP } 1.220 \pm 40 \\
\text { AD } 730 \pm \mathbf{4 0}\end{array}$ \\
\hline
\end{tabular}

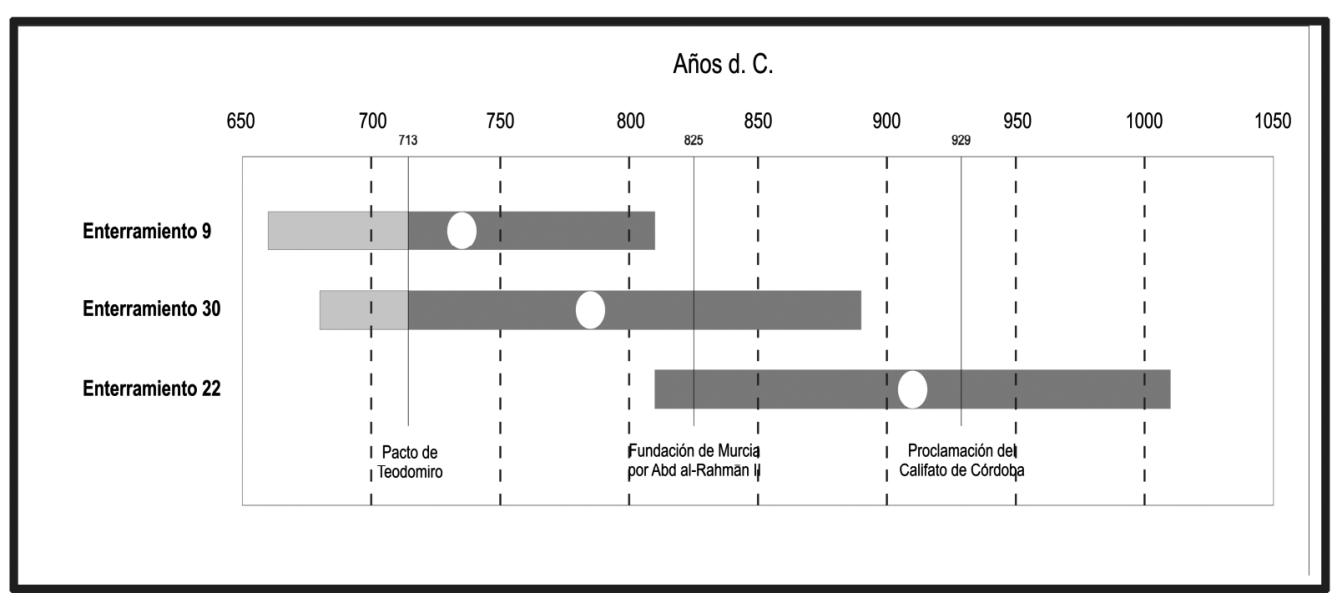

Figura 1: Representación gráfica de las dataciones radiocarbónicas obtenidas mediante el método AMS, aplicando el intervalo de dos sigmas y la fecha central de la horquilla temporal. Las analíticas han sido realizadas por Beta Analytic Radiocarbon Dating Laboratory de Miami.

las actuaciones sistemáticas de la última década, han dado como resultado la constatación de la ocupación del solar como espacio mortuorio en época islámica (Fig. 2). A las dieciséis inhumaciones vagamente documentadas por J. Lafuente Vidal y F. Figueras Pacheco, hay que sumar un total de cinco sepulturas localizadas en sectores muy dispersos (Olcina Doménech y Pérez Jiménez, 1998, 50). A principios del año 1998, momento en el que se lleva a cabo la primera actuación sistemática en el Tossal de Manises, se localiza un nuevo enterramiento. Al año siguiente, los trabajos se centran en el área suroriental del yacimiento, hallándose un total de veinte inhumaciones de rito islámico. El número tan elevado y concentrado de tumbas en este espacio nos hizo plantear la hipótesis de existencia de una necrópolis que se extendía hacia la Torre del Toro (en dirección SO) y sus cercanías, allí donde se habían descubierto las primeras sepulturas, supuesto que, durante los tres años siguientes, fue corroborado, contabilizándose un total de sesenta y siete nuevos enterramientos. El número total de tumbas a día de hoy (Fig. 3), asciende a un mínimo de ciento ocho individuos musulmanes, y uno asociado al rito cristiano (Tendero Porras, Guilabert Mas y Olcina Doménech, 2007).

\subsection{LOS ENTERRAMIENTOS}

El desconocimiento de las características morfológicas de las inhumaciones descubiertas en los años treinta, hacen que el estudio se ciña a los localizados desde la década de los noventa, es decir, los exhumados con criterios actuales.

El lugar de la maqbara no parece corresponder al azar sino que obedece a una serie de rasgos comunes, visibles en la mayoría de las maqabir analizadas. Se localiza en una ladera ${ }^{2}$; se sitúa cerca del mar (Casal García, 2003, 22) 3 $^{3}$ unque, en la actualidad, la relación visual entre la maqbara y la línea de costa se encuentra desvirtuada (Fig. 4), dada la agobiante presión urbanística sufrida en la zona (Tendero Porras, Guilabert Mas y Olcina Doménech, 2007, 138);

2. Se documenta tanto en yacimientos junto a la línea de costa, caso del Cerro del Almendro en Marbella (Fernández Rodríguez et alii, 2001, 613), o de interior, como en el Tolmo de Minateda en Hellín (Gutiérrez Lloret, 1996, 305).

3. Hay paralelos en oteros cuya ladera vierte hacia el mar -necrópolis del Maraute en Motril (Gómez Becerra y Malpica Cuello, 1999, 191)- o en la misma playa -Cerro del Almendro de Marbella (Casal García, 2003, 21-22)-. 


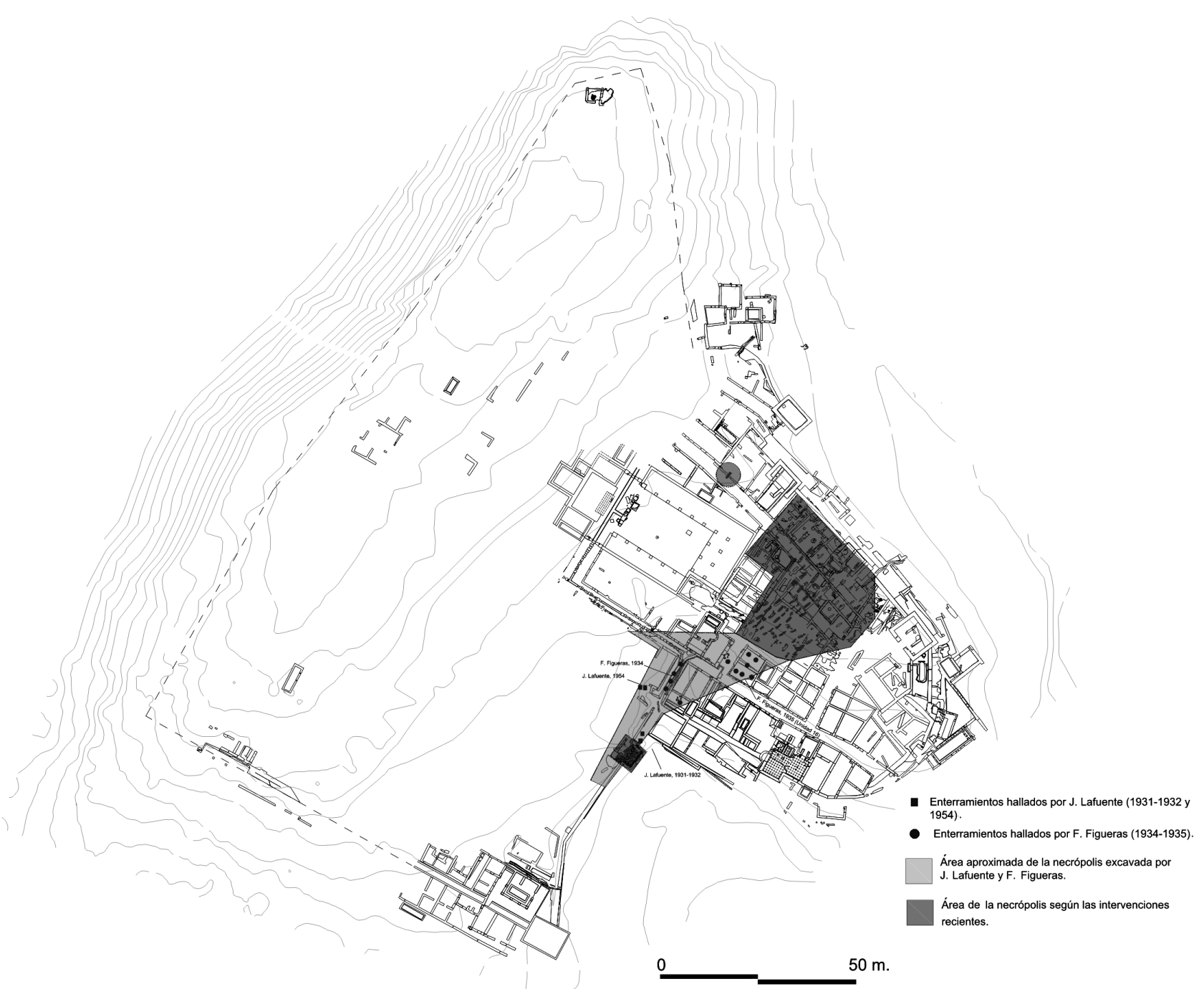

Figura 2: Plano de localización de la maqbara del Tossal de Manises, donde se incluye la ubicación de las sepulturas exhumadas desde los años 30 hasta la actualidad.

finalmente, se relaciona con puntos de agua, vinculación plasmada en numerosas maqabir peninsulares, localizadas junto a acuíferos subterráneos, ramblas, fuentes, arroyos, cursos de ríos, torrenteras o barrancos, que sirven o bien como límite externo o bien como separación ${ }^{4}$. En el caso de la maqbara del Tossal de Manises, además de su cercanía al mar, su vertiente E se inclina hacia un marjal, La Albufereta (desecada desde el año 1928), lugar hacia el que desaguaba de forma esporádica la Rambla de Orgegia-El

4. En la península, encontramos varios ejemplos de localización de maqābir en ramblas -Yakka (Ruiz Molina, 2000a, 199; 2000b, 22)-, fuentes - calle Corredera en Alhama de Murcia (Ramírez Águila y Urueña Gómez, 1998, 370)-, arroyos - como los que atraviesan Marroquíes Bajos en Jaén (Serrano Peña y Castillo Armenteros, 2000, 98), el de Tobarra, junto al cerro del Tolmo de Minateda (Abad Casal, Gutiérrez Lloret y Gamo Parras, 2004, 145, fig. 1)- o incluso en torrenteras -Yābal Fāruh en Málaga (Fernández Guirado, 1995, 41-42 y 56 , fig. 1)-.
Juncaret, amén de contar con la existencia de un manantial de agua dulce en el cercano Tossal de les Basses (Rosser Limiñana et alii, 2004, 137). La vinculación de la maqbara con el agua, queda reforzada por la existencia de un cauce menor que divide en dos el área destinada a inhumaciones en el yacimiento, que parte desde la superficie del solar del foro hasta la Torre del Toro (Tendero Porras, Guilabert Mas y Olcina Doménech, 2007, 139). Otro punto relacionado con la ubicación de una necrópolis es la necesaria cercanía a algún núcleo de hábitat, en sus proximidades o junto a los caminos de acceso (Torres Balbás, 1983, 235 y ss.; Macias, 2001, 55), cuestión no resuelta por el momento. El último asunto estriba en la existencia de dos ritos distintos compartiendo espacio funerario. La bibliografía muestra contradicciones: por un lado la consideración de las necrópolis de otras culturas como lugares impíos y, por tanto, inhábiles para enterrar a sus difuntos (Alba Calzado, 2005, 339) y, por otro, la evidencia arqueológica junto a algunos autores que afirman que la tradición mortuoria en un mismo 


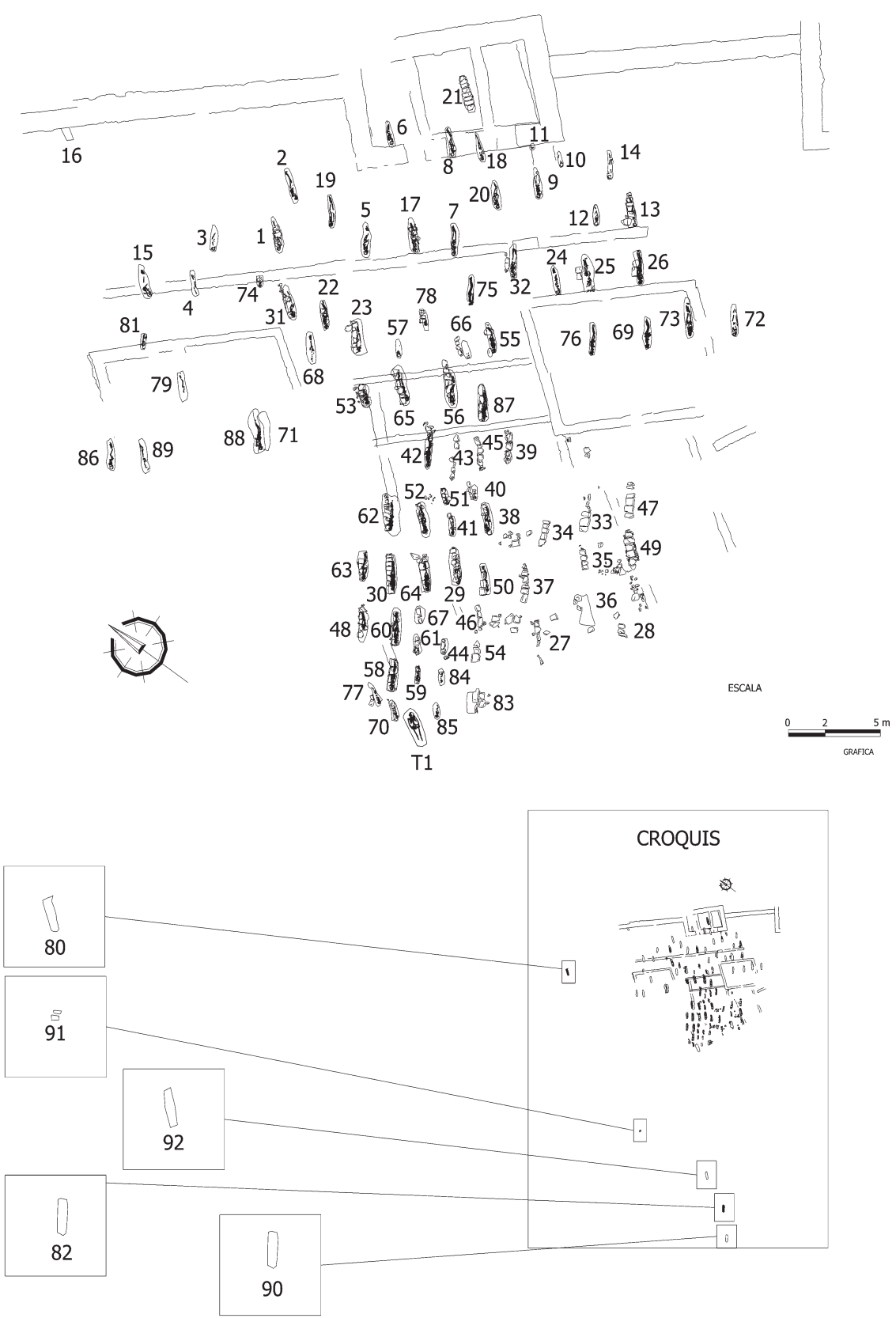

Figura 3: Distribución de las tumbas en la maqbara.

sitio es síntoma de baraka $^{5}$ y, por tanto, lugares susceptibles de seguir siendo utilizados como espacio mortuorio (Ramírez Águila y Urueña Gómez, 1998, 355), a la que se unen factores como la costumbre,

5. Especie de gracia mística benéfica que pueden emanar tanto lugares (ciudades como La Meca o las mezquitas, puntos relacionados con el agua), como ciertas personas (los que conocen de memoria el Libro Sagrado, los niños pequeños, los ancianos, los locos inocentes), incluso seres vivos (los olivos, las palmeras, el laurel, los bosques), objetos (El Corán, la Piedra Negra) y determinados momentos (la vigésimo séptima noche del Ramadán). el desconocimiento o el parentesco, explicando la desatención de la sharia 6 (Tendero Porras, Guilabert Mas y Olcina Doménech, 2007, 141). En el Tossal de Manises se ha localizado un único enterramiento de rito cristiano vinculado al conjunto islámico. Los análisis antropológicos han revelado que se trata de una mujer adulta (Rodes Lloret et alii, 2000) y, aunque no se ajusta totalmente a la retícula, las sepulturas

6. Literalmente es el «camino al manantial». Es el cuerpo del derecho islámico, un detallado código de conducta a seguir, englobando la normativa del culto, la moral y la vida. 


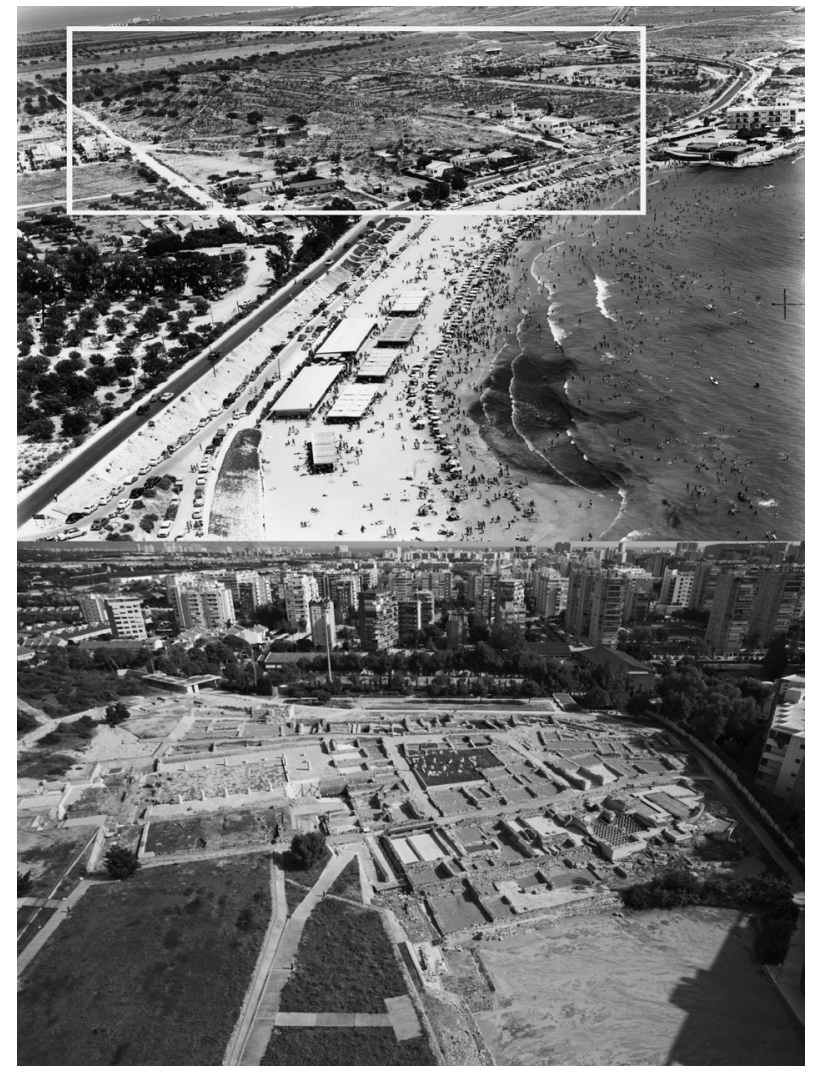

Figura 4: Imágenes aéreas comparativas del entorno del yacimiento. En la parte superior aparece una fotografía tomada en la década de los 60 con el yacimiento enmarcado. La imagen de la parte inferior, tomada en 2007, muestra la fuerte presión urbanística que sufre el enclave.

islámicas no sólo respetan esta inhumación sino que, además, ésta se encuentra rodeada por enterramientos infantiles musulmanes. Se barajan hipótesis como el parentesco o la tradición mortuoria en la zona, independientemente de su religión, aunque no tenemos datos suficientes para explicar este fenómeno.

\subsubsection{La organización del área cementerial}

La maqbara se articula en dos sectores delimitados por una rambla interior en dirección NE-SO. El Sector Sur se ha excavado en su periferia, mientras que en el Norte se ha actuado en extensión. La planta de la necrópolis desvela la existencia de un «parcelario» con una disposición de las tumbas en retícula marcándose «calles» en sentido longitudinal y transversal (Fig. 5), quizá concebidas no sólo para el devenir de los visitantes evitando que el calzado las roce ${ }^{7}$, sino también para facilitar el paso de los cortejos fúnebres (Tendero Porras, Guilabert Mas y Olcina Doménech, 2007, 146). La distancia longitudinal entre las tumbas oscila en

7. Esta norma no queda recogida en la sharia, aunque se lleva a cabo ampliamente en todo el Islam (Dickie, 1985, 46). torno a los $40 \mathrm{~cm}$, mientras que la transversal supera, ampliamente, el $1.40 \mathrm{~m}$. La orientación dominante de las tumbas es SO-NE, con las caras vueltas al SE (Fig. 6), ubicación típica de las qiblas de primera época islámica (Gutiérrez Lloret, 1996, 304-305), aunque se observan variaciones que podemos agrupar en tres áreas distintas, dentro del mismo plano y sin superposición, ya que parecen sincrónicamente ocupadas.

\subsubsection{Las inhumaciones: el rito como instrumento}

En ocasiones, el registro arqueológico se queda mudo cuando le realizamos una serie de preguntas acerca del ritual funerario. Es por ello por lo que se hace necesario el uso de otras vías de información, puesto que, los rituales en torno a la muerte, en la mayoría de las culturas, poseen un carácter conservador (Chapa Brunet, 1991). Dada la naturaleza del registro exhumado en el Tossal de Manises, tumbas sin ajuar ni materiales asociados, surgió la necesidad de intentar comprender el fenómeno mortuorio en toda su extensión, por lo que a través del rito analizamos diferentes elementos aparecidos en la excavación. Se han utilizado las fuentes escritas de la época -textos mudéjares y moriscos- donde describen las exequias, cuya rígida normativa perduró hasta su expulsión (Roselló Bordoy, 1992, 162), así como itinerarios del siglo $\mathrm{XV}$ y procesos inquisitoriales, que nos aportan datos

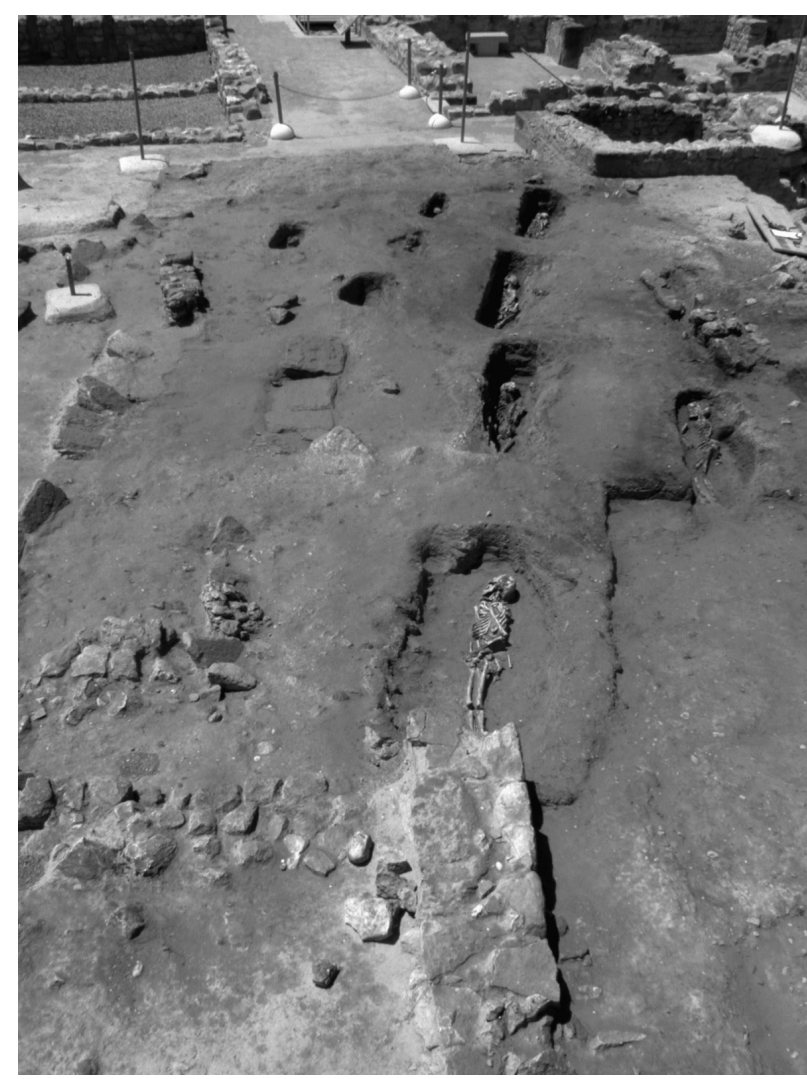

Figura 5: Organización en calles de la maqbara. 


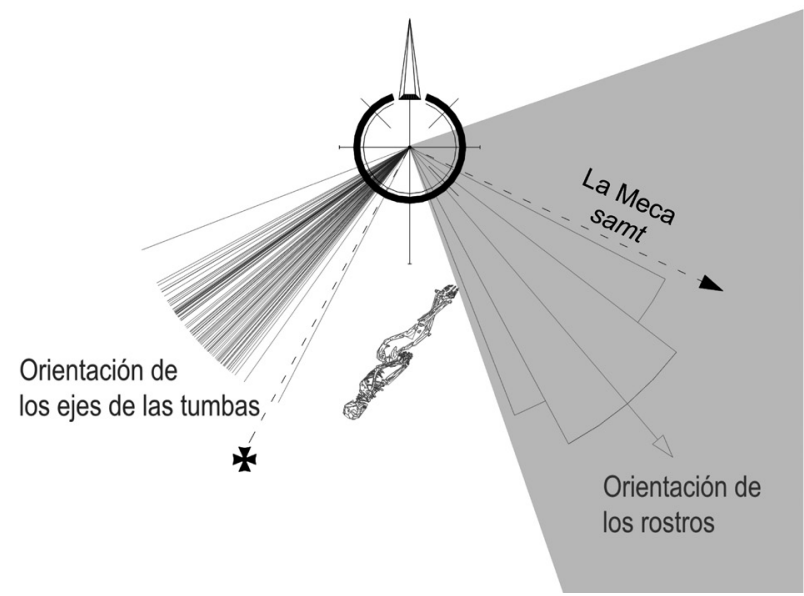

Figura 6: Orientaciones de los ejes de las tumbas y los rostros de los cadáveres. El área tramada corresponde a la $\hat{y} i h \bar{a}$, ángulo de $90^{\circ}$ en cuyo centro se encuentra el samt, que es el punto exacto hacia el que se dirige la qibla.

de las costumbres que en ocasiones se nos muestran contradictorios; en segundo lugar los datos que nos proporcionan tanto la etnografía como los estudios de cultura contemporánea, puesto que el Islam, catorce siglos después de producirse la Hégira, se mantiene fiel a la sharia, abarcando su jurisprudencia la totalidad de las facetas de la vida y la muerte de un musulmán donde el rito, prácticamente, se mantiene estático ${ }^{8} ; \mathrm{y}$, por último, el registro arqueológico ${ }^{9}$, que no puede ser estudiado en su totalidad, pues se circunscribe a actuaciones en el área occidental, ya que los trabajos en el ámbito de la muerte se encuentran vedados en los países que poseen mayoría musulmana (Pozo Martínez y Hernández Carrión, 2000, 417).

Hay una serie de elementos que no siempre dejan huella en el registro arqueológico, que comprenden diferentes tratamientos físicos al difunto y oraciones por su alma. Estos rasgos, que se recogen dentro del rito post mortem, consisten en preparar el cuerpo para el entierro $(\text { dafan })^{10}$ cerrándole los ojos y la mandíbula para después pasar al ritual del lavatorio o gusul, que afecta tanto al que lo hace como al difunto, al que se

8. La religión islámica se basa en la revelación de Alá a Mahoma, recogida tanto en el Corán como en la sunna (la «tradición»), por lo que, su seguimiento, hace que el rito funerario islámico permanezca prácticamente inmutable, al menos en lo esencial, a lo largo del tiempo.

9. En ocasiones, los datos que nos proporciona la arqueología se muestran contradictorios, quizá relacionados con el reflejo en el terreno de diferencias locales o, como señala G. Roselló Bordoy $(1992,162)$, con las características físicas del terreno y donde, la cronología, funciona como una variante de relevancia que deriva, posiblemente, en una falta de homogeneidad ritual en los primeros tiempos del islamismo.

10. La mayoría de la terminología referente al ritual, ha sido extraída de fuentes y prontuarios actuales. le realizan tres abluciones (Casal García, 2003, 38; Jover Maestre et alii, 2005, 24), comenzando por el lado derecho como lugar de privilegio (Baños Serrano y Martínez López, 2004, 334, nota 8; Ponce García, 2002, 116; Pozo Martínez, 1990, 114) a la vez que se recita «en el nombre de Dios, y acorde a las enseñanzas de Su Mensajero» ${ }^{11}$. A continuación se procede al amortajamiento del cuerpo (takfin o kafan) que ha de ser realizado por personas del mismo sexo que el difunto (Longás Bartibás, 1990, 287) al que, previo tapado de los orificios corporales con algodón y alcanfor o kāfür (Ponce García, 2002, 116), se le coloca una mortaja blanca (Jover Maestre et alii, 2005, 24; Martínez Rodríguez, 2002, 20) o amarillenta y a ser posible de algodón (Casal García, 2003, 39; Abd Al Fatah García, 2001, 34, nota 7), pero siempre en número impar, tres, cinco o siete (Ramírez Águila y Urueña Gómez, 1998, 350; Casal García, 2003, 39), que posteriormente se cose (Casal García, 2003, 39; Jover Maestre et alii, 2005, 24). Ninguno de los restos exhumados en la maqbara del Tossal de Manises ha conservado restos de la mortaja, elemento que, con toda seguridad, portaba cada uno de los inhumados ${ }^{12}$, por el aspecto compacto de los cuerpos y disposición de sus extremidades (Fig. 7). Seguidamente, se lleva a cabo la oración de los funerales o salatul-yanaza a cargo de un imām y donde, sin ruku' (inclinación) ni suyud (postración), se recita en cuatro ocasiones la plegaria o takbirah «Alá es el más grande» (Ponce García, 2002, 117); con posterioridad se traslada el féretro al cementerio en andas o parihuelas (Pozo Martínez, 1990, 115) cubierto por un lienzo o un manto (Ponce García, 2002, 116; Pozo Martínez, 1990, 115) y llevado por portadores que se renuevan constantemente (Longás Bartibás, 1990, 290), que entonan aleyas del Corán (Ponce García, 2002, 117). El traslado hacia la tumba es acompañado por el cortejo fúnebre o tashïi al-yanaza para el que todos los participantes han sido previamente purificados (Longas Bartibás, 1990, 288; Casal García, 2003, 39) y, finalmente, antes de introducirlo en la fosa, se realizan oraciones a pie de tumba, un total de cuatro veces (Longás Bartibás, 1990, 289), colocando el cuerpo en perpendicular a la qibla.

Se han de cumplir una serie de condiciones a la hora de elegir el lugar donde ubicar la tumba, a ser posible en las cercanías del muro de la qibla (Dickie, 1985, 31) o entorno a personas que intercedan por el recién fallecido ( $\check{s} a f a ̈ h ' a)$ pues ambos elementos emanan una especie de gracia mística o baraka.

11. Extraído de «Los funerales en el Islam» (www.islamerica. org.ar/dofune1.html).

12. Los análisis sedimentológicos y óseos del yacimiento (Seva Román et alii, 2007, 89), señalan que el problema derivado de las propiedades del terreno, donde la acción del cloruro sódico degrada cualquier resto orgánico de forma notoria, es la causa directa de la no conservación de los lienzos de la mortaja funeraria y de algunos restos óseos. 


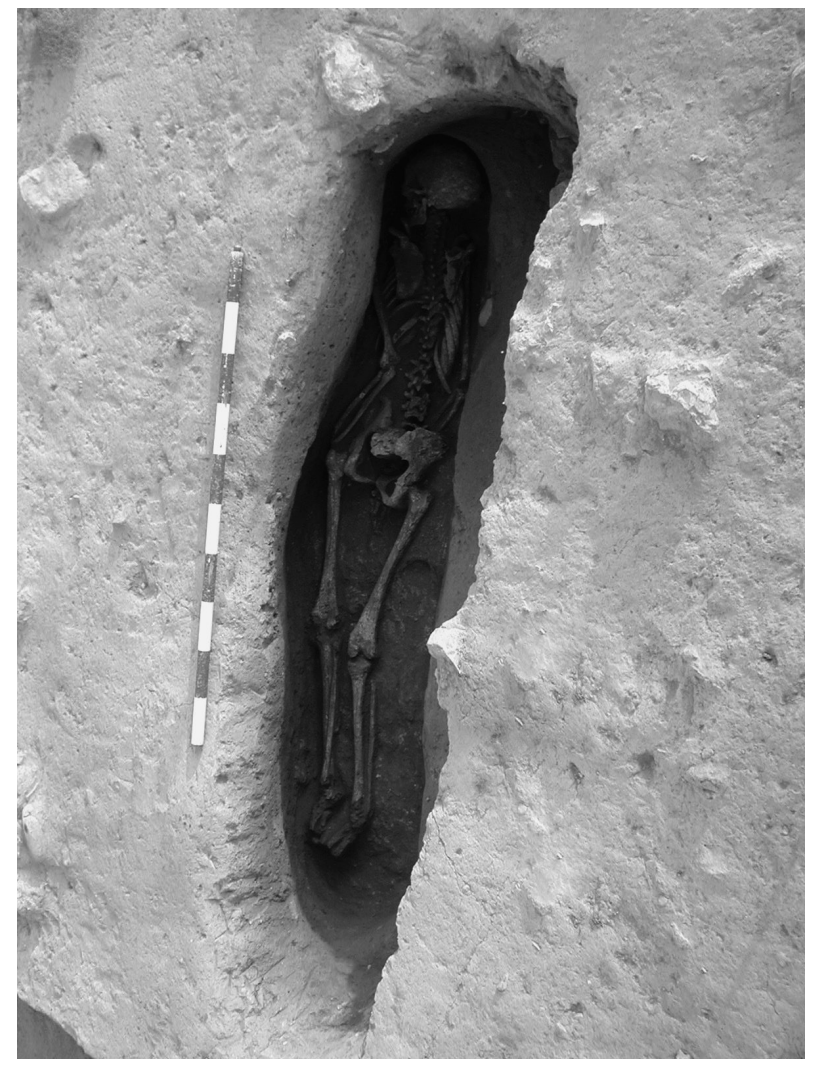

Figura 7: E87, donde se muestra el cuerpo ajustado dentro de una reducida fosa que, a su vez, está provista del escalón lateral donde quedarían apoyadas las losas a un agua. También cuenta con la existencia de shaq, lajd o covacha lateral, donde el cuerpo quedaría parcialmente encajado.

Junto a estos factores, se han de tener en cuenta una serie de prohibiciones. Marcan los preceptos que las tumbas no han de estar ubicadas en el interior de las mezquitas ni estar concebidas como monumentos ${ }^{13}$. En ningún caso se ha de colocar más de un individuo en su interior (Casal García, 2001, 288; Márquez Pérez, 2005, 305), como indica Jerónimo Münzer, en un itinerario del siglo XV donde señala que «cada sarraceno se entierra en una sepultura nueva y propia» (Espinar Moreno y Quesada Gómez, 2000, 93), ni tampoco es posible reutilizar las tumbas hecho, por otro lado, constatado en el Tossal de Manises donde se documentó un conato de fosa, el denominado E71, que nunca llegó a ser ocupado, pues durante su excavación dieron con los restos de la inhumación número 88, que fue respetada. Dentro de esta jurisprudencia se regulaban prohibiciones como el uso de ataú-

13. En cambio, la realidad arqueológica nos muestra que, por un lado, en la maqbara de Yābal Fāruh (Málaga) se han documentado las dos únicas mezquitas con claro carácter funerario en al-Andalus (Fernández Domínguez, 1995, 77) $\mathrm{y}$, por otro, la constatación de que la arquitectura funeraria incluye numerosas obras de arte (Dickie, 1985, 29). des ${ }^{14}$, así como la de portar cualquier tipo de ajuar ${ }^{15}$, normativas que se cumplen sin excepción en el Tossal de Manises.

A partir de este punto, muchos de los elementos a seguir en el ritual mortuorio islámico son susceptibles de dejar huella en el registro arqueológico, pues son de índole física y por tanto, fácilmente rastreables. Las sepulturas $(q u b \bar{u} r)$, dado el esquema sobrio y sencillo, donde el boato, el fasto y la apariencia no tienen cabida, se ciñen a estrechas fosas excavadas en el suelo o en la roca y cuya tipología parece atender a las propiedades del terreno en el que se practica, a las modas que se suceden, a las creencias, a las influencias y a las tradiciones. En el caso del Tossal de Manises ${ }^{16}$, las fosas se agrupan, a priori, dentro de dos amplios conjuntos: simples y con escalón lateral con algunas variantes, así como un grupo de sepulturas con tipología singular. Las más numerosas son las tumbas que cuentan con fosa simple, un total de cuarenta y ocho, que presentan escasas variantes. Con respecto al trazado de los extremos, la mayoría, cuarenta y un ejemplares, los presentan redondeados, en cinco casos son mixtos (E8, E26, E55, E71 y E81), en uno la cabecera es irregular y la parte inferior redondeada (E88) y por último, tenemos una sola fosa donde sus límites son rectos (E13). De las paredes del conjunto formado por fosas simple, treinta y seis son rectas y el resto cónca$\operatorname{vas}^{17}$. Las bases de las fosas son bastante homogéneas y carecen de cualquier tipo de preparado, tienen tendencia horizontal y un leve rehundimiento en la parte central; en dos inhumaciones (E41 y E52), la base se realiza sobre estructuras de cronología anterior.

14. Por otro lado, a pesar de este veto, los datos arqueológicos revelan no sólo la existencia de este tipo de elementos por la presencia de clavos, argollas (Márquez Pérez, 2005, 289; Ponce García, 2002, 117) o restos de madera (Pascual Pacheco y Serrano Marcos, 1996, 240) sino, incluso, su proliferación a partir de finales del siglo XI o principios del XII (Peral Bejarano, 1995, 23; Pascual Pacheco y Serrano Marcos, 1996, 247), donde se constata además, un ligero ensanche de las fosas (Casal García, 2001, 288; 2003, 32).

15. Hay autores que designan a los «ajuares» con el eufemismo de «depósitos funerarios» (Menchón i Bes, 1998, 13; Tomassetti Guerra et alii, 2005, 109), definiéndolos como los artefactos que acompañan al difunto. Los elementos más comunes son candiles (Pujante Martínez, 2004, 400), orzas (Galve Izquierdo, 1995, 127, nota 22), jarritas (Curto Homedes et alii, 1986, 657), jarros (Tomassetti Guerra et alii, 2005, 110) y redomas (Martínez García et alii, 1990, 75).

16. Para el estudio pormenorizado de la tipología del conjunto de sepulturas del Tossal de Manises, que asciende a un mínimo de ciento nueve, hay que restarle las excavadas entre los años 30 y 50 (de las que apenas tenemos información), así como aquellas que han sido dejadas en reserva en las zonas musealizadas. El resultado es un estudio de setenta $\mathrm{y}$ dos fosas.

17. Es posible que este tipo de paredes laterales cóncavas podamos ponerlas en relación con la existencia de covachas o shaq, atestiguadas en las tumbas mejor conservadas, como veremos más adelante. 
El segundo gran conjunto, con un total de veinte ejemplares contabilizados, es el de las fosas con escalón lateral dispuesto longitudinalmente de $\mathrm{NNO}$ a ONO, pudiendo alcanzar los extremos de la misma (ver figura 7). Este tipo de tumbas se concentran preferentemente en la denominada área nuclear de la maqbara extendiéndose hacia el NE, zona coincidente con aquellas sepulturas mejor conservadas. Parece ser que la existencia de este escalón lateral es puramente funcional, siendo el lugar donde apoyaban las losas de la cubierta, a modo de tejadillo vertiendo al NO. La mayoría de estas sepulturas (un total de dieciocho) cuentan, en la zona opuesta al escalón, con una especie de covacha lateral, que recibe el nombre de lajd (Abd Al Fatah García, 2001, 25) o shaq ${ }^{18}$ (ver figura 7), hecho intencional pero escasamente documentado y/o descrito en las maqābir peninsulares, aunque cuenta con paralelos como la de Bāb Baŷyāna en Almería (Alcaraz Hernández, 1990, 16 y 18, fig. 4) o en la N4 de Marroquíes Bajos en Jaén (Serrano Peña y Castillo Armenteros, 2000, 97), siendo difícil rastrear la raíz y posterior difusión de esta práctica funeraria.

Por último, encontramos cuatro ejemplares que no podemos incluir en ninguno de los otros tipos. El E11, es una pequeña fosa que contiene un cráneo y cuya interpretación es controvertida pues, por un lado hay autores que niegan la posibilidad de la existencia de inhumaciones secundarias en el mundo funerario islámico (Dickie, 1985, 46) y por otro, la realidad arqueológica, con la presencia de depósitos de este tipo en Madīnat Bāguh en Priego, Córdoba (Carmona Ávila y Luna Osuna, 1996, 121). La fosa de inhumación del E25 se caracteriza por la presencia de un escalón circundante, por lo que quedaría dentro del tipo, no presente en ningún caso más en el Tossal de Manises, conocido como tumbas con prefosa, similares a las del tipo II de la N2 de Marroquíes Bajos (Serrano Peña y Castillo Armenteros, 2000, 103). El E53 posee una fosa de planta oval con escalón lateral y en su interior un niño en posición fetal, cuyo único paralelo se localiza en la calle Corredera $\mathrm{n}^{\mathrm{o}} 16$ de Alhama de Murcia (Baños Serrano et alii, 2004, 101). La última de las fosas excepcionales es la de E62, con una planta oval de grandes dimensiones (2.36 m de largo y $1.03 \mathrm{~m}$ de ancho).

Hay una serie de rasgos que se encuentran presentes en la práctica totalidad de las sepulturas excavadas pues poseen un trazado ahusado más amplio en la cabecera y, además, tienden a estrecharse en la zona de la base, donde queda encajado el cuerpo. Una última peculiaridad no fue atestiguada durante el proceso de excavación, sino proporcionada por los análisis de difracción de rayos $\mathrm{X}$ (XRD), que muestran la posibilidad del uso

18. Receptáculo lateral en el que se dispone el cadáver, ya descrito por diversas fuentes para la tumba del Profeta (extraído de «Los funerales en el Islam» en la página www.islamerica.org.ar/dofune1.html).

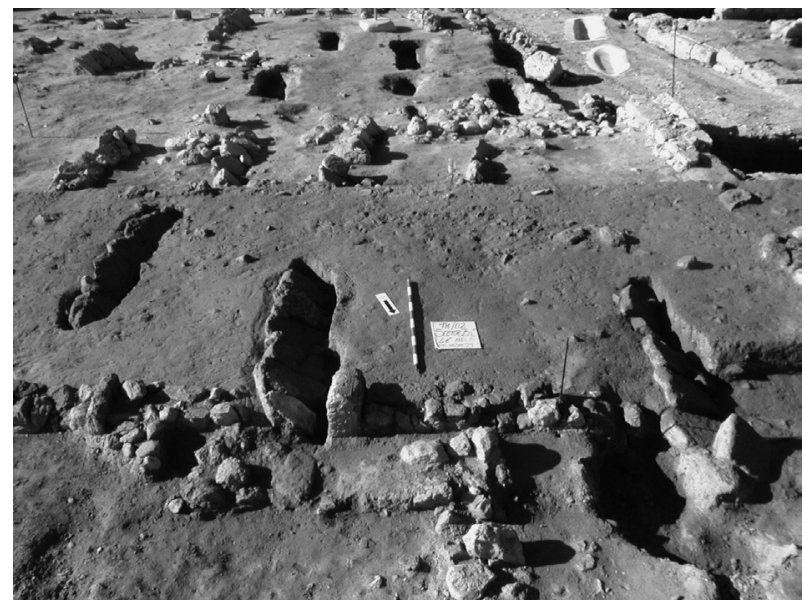

Figura 8: Disposición de las tumbas de la maqbara. Se aprecian las alineaciones en calles longitudinales y transversales, la orientación de los ejes de las tumbas en dirección SO-NE y la inclinación de las losas que componen la cubierta hacia el NNO-ONO.

de cales hídricas apagadas y yeserías en la confección de las tumbas (Seva Román et alii, 2007, 75). A pesar de las diferencias tipológicas, no podemos descartar que el conjunto de la maqbara perteneciera en origen a un solo tipo de tumba, el que posee escalón lateral, encontrándonos el resto afectadas por la erosión y la degradación, antrópica o natural, estando parcialmente sesgadas, sobre todo en las cotas más altas, pasando de ser fosas con escalón lateral a fosas simples.

La colocación del finado dentro de la tumba es síntoma inequívoco de su adscripción cultural islámica, pues el precepto marca que han de depositarse en decúbito lateral derecho con la cara orientada hacia $\mathrm{La}$ Meca, es decir, al SE, buscando la perpendicular con respecto al eje del mihrāb, en posición paralela a la $q i$ bla (Ruiz Molina, 2000a, 199), con el eje de la tumba NE-SO (Casal García, 2001, 288). La variación en la disposición final de brazos o piernas no es un hecho intencional, sino relacionado con el rigor mortis en el cadáver o con procesos postdeposicionales. En la maqbara del Tossal de Manises, de los setenta y un cuerpos exhumados, sesenta se colocan en decúbito lateral derecho (treinta y siete leves y veintitrés en grado total); en nueve ocasiones no se ha podido determinar por el mal estado de los huesos; uno de ellos está en posición fetal (E53) y otro se encuentra en decúbito prono (E73). Sí se ha documentado una clara intencionalidad en acomodar al cuerpo en decúbito lateral derecho, con la colocación de elementos en el torso o el cráneo que permita mantener al cadáver en esta posición tan inestable (Botella Ortega et alii, 2005, 25; Carmona Ávila y Luna Osuna, 1996, 119 y 1999, 175). El ritual funerario marca que, una vez introducido el cuerpo en la tumba, se ha de proceder al descosido de la mortaja en ambos extremos (Jover Maestre et alii, $2005,24)$ e introducirlo dentro de la cavidad lateral de la fosa $\mathrm{o}$, en ocasiones, procurar confeccionar sobre el 
cadáver una especie de cámara hueca (Casal García, 2001, 288; Ponce García, 2002, 117; Pozo Martínez, 1990, 115 y 1992, 417; Serrano Peña y Castillo Armenteros, 2000, 99-100; Ramírez Águila y Urueña Gómez, 1998, 352) con la finalidad de que pueda incorporarse para el interrogatorio de los ángeles. En el caso del Tossal de Manises, a pesar de contar las fosas con cavidad lateral (shaq o lajd) y cubierta de losas, en sólo uno de los enterramientos (E50) se ha documentado una pequeña cámara hueca. Antes de proceder al sellado de la tumba, la tradición señala que hay que introducir en la tumba la denominada carta de la muerte. Es un pergamino o papel en el que se escriben con azafrán una oración y una petición de perdón de los pecados (Longás Bartibás, 1990, 294-295; Jover Maestre et alii, 2005, 24; Ponce García, 2002, 117), no atestiguada en ninguna tumba del yacimiento.

Con posterioridad se procede al sellado de la tumba $y$, al respecto, la arqueología nos muestra una importante relajación a la hora de seguir la norma de sobriedad. Las hay que usan piedras, elementos reutilizados, adobes, tablones de madera o túmulos. En el caso de las cubiertas documentadas en la maqbara del Tossal de Manises, que presentan diversos grados de conservación, se realizan con losas, piedras, escasos elementos de construcción reutilizados y se ha documentado, incluso, que en algunas de las tumbas, los componentes de cubrición se afianzan con calzos. Todas ellas se orientan en la misma dirección que las fosas (SO-NE), siendo el rasgo dominante su posición inclinada hacia el NNO-ONO (Fig. 8), de modo que

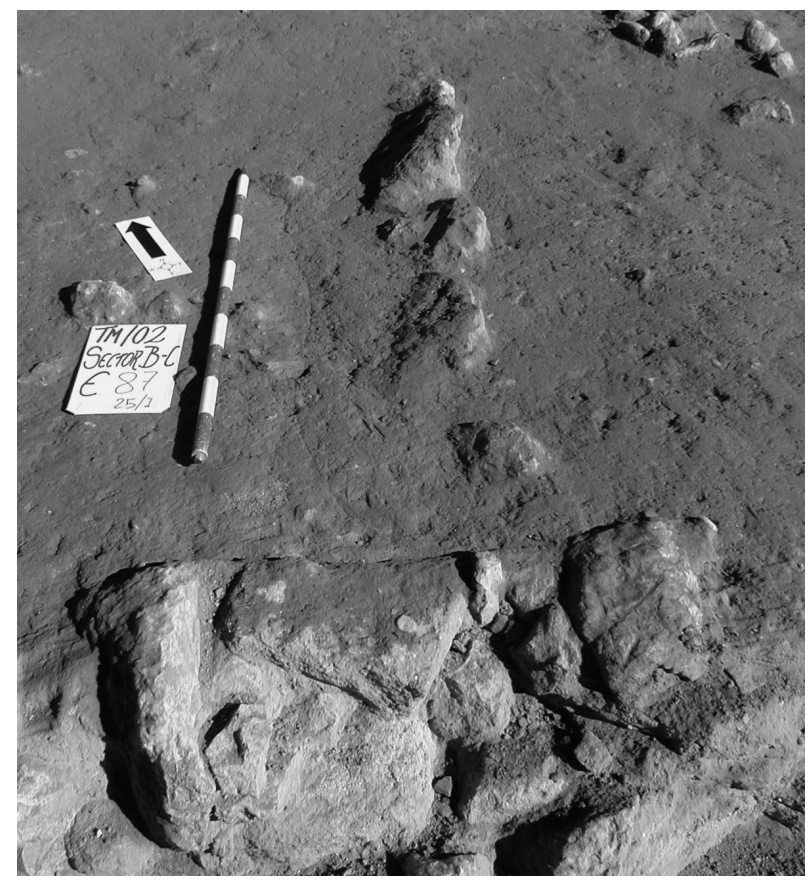

Figura 9: E56, dotado de sobrecubierta que rellena parcialmente la fosa y la parte inferior de las losas de cubrición y los calzos, donde se aprecia el resultado de la taswiyat al-qubur o igualación de la tumba con respecto al suelo que la rodea. protegen la parte dorsal del difunto, con paralelos con losas o piedras en El Tolmo de Minateda en Hellín, Albacete (Gutiérrez Lloret, 1996, 304; 2007, 344), en el Paraje de la Era del Lugar en Mojácar, Almería (Alcaraz Hernández y San Martín Montilla, 1992, 30) y en al menos una sepultura localizada en Águilas, Murcia (Hernández García, 2004, 446-447, lám. 4) ${ }^{19}$. El proceso de colocación es recurrente, comenzando desde la zona de la cabecera (donde solemos encontrar las de mejor factura) y culminando en la de los pies. En aquellas sepulturas mejor conservadas, sobre todo las de la zona central de la maqbara, las losas de la cubierta no afloraban en su totalidad, sino únicamente la parte superior de las mismas, quedando el resto en el interior de la fosa. El hueco resultante es posteriormente rellenado por lo que hemos denominado sobrecubierta, elemento para el que no hemos encontrado paralelo arqueológico, pero sí una referencia descrita por J. Sourdel-Thomine (1991, 367), definida como taswiyat al-qubūr o igualación de la tumba con respecto al terreno que la rodea, enrasándola con el nivel de tránsito (Fig. 9). Por último, no podemos descartar la posibilidad de la existencia de túmulos que ocultaran la cresta superior de las tumbas, aunque a día de hoy no se ha encontrado ninguna evidencia arqueológica.

Tanto el descosido de la mortaja como la creación de una especie de cámara hueca al introducir el cuerpo, son hechos realizados ex professo con la finalidad de facilitar la incorporación del difunto la misma noche del entierro y las siguientes, momento en el que se lleva a cabo el interrogatorio de la tumba, el juicio en la fosa o de los ángeles (Casal García, 2003, 40). El nombre de los ángeles puede variar según la transcripción ${ }^{20}$, pero la finalidad es la misma: someter al difunto a juicio acerca de su Fe, Allah y su Profeta. Dependiendo del veredicto, el alma del creyente puede ir al

19. Hay ejemplos de cubiertas a un agua en los que los materiales empleados son otros: con lajas -Cerro del Almendro de Marbella, Málaga (Fernández Rodríguez et alii, 2001, 618), en algunas de las tumbas de Xarea en Vélez Rubio, Almería (Haro Navarro y Carrión Méndez, 1999, 12-13), algunas sepulturas de la maqbara medieval de Baza, Granada (Ríos Frutos y Pérez Asensio, 2008, 92, fig. 5) y en la maqbara de Bāb al-Tulaytulat en Zaragoza (Galve Izquierdo y Benavente Serrano, 1992, 385)-; con sillarejos y tejas inclinados -Madinnat Bāguh en Priego de Córdoba (Carmona Ávila y Luna Osuna, 1996, 124; 1999, 183)-; con tegulce-Yakka (Yecla) en Murcia (Ruiz Molina, 2000a, 56) y también en Bāb al-Tulaytulat en Zaragoza (Galve Izquierdo y Benavente Serrano, 1992, 385), donde además hay otro tipo realizado con adobes inclinados- $y$, finalmente, con tablas de madera y piedras a un agua -Marroquíes Bajos, Jaén (Serrano Peña y Castillo Armenteros, 2000, 103-104 y 116-117, figs. 9 y 10)-.

20. Móncar y Naquir (Longás Bartibás, 1990, 295); Munkar y Nankir (Pozo Martínez, 1990, 115); Muncar y Nakir (Pozo Martínez y Hernández Carrión, 2000, 417); Munkar y Nakir (Ponce García 2002, 117); Munker y Nakīr (Márquez Pérez, 2005, 306) o Munkir y Nakì (Casal García, 2003, 40). 
Paraíso $^{21} \mathrm{o}$, por el contrario, ser azotado con un látigo que lanza llamas para ser enviados hacia la gehena o el Infierno (Casal García, 2003, 40). Es en este momento cuando todos los difuntos sufren el denominado castigo de la tumba o 'adzāb al-qabr, una purgación de sus pecados durante los siete días siguientes al sepelio, donde la sepultura arde y desprende calor. Los familiares y amigos pueden aliviar este ardor con la práctica de «refrescar la tumba» ${ }^{22}$, realizando abluciones sobre la sepultura y sembrando plantas alrededor (Tomassetti Guerra et alii, 2005, 118). Estos autores ponen en relación con esta costumbre el hallazgo de diferentes formas de cerámicas abiertas que en el caso del Tossal de Manises se reduce a un único elemento, exhumado en las excavaciones de F. Figueras Pacheco (1971, núm. 99). Se trata de un jarrito de la forma T20 (Gutiérrez Lloret, 1996, 113-115), posiblemente asociado a los rezos y visitas al cementerio. A continuación se produce un segundo encuentro, en este caso con Dios, que realiza el «juicio del alma», colocando sus acciones en una balanza, para pesar su espíritu (Márquez Pérez, 2005, 306). Si el veredicto es satisfactorio se cruza un puente que queda tendido sobre la gehena y que deriva en la «cuenca de Mahoma», donde quien beba de sus aguas aplacará por siempre su sed, tras la que se encuentra el Paraíso (Márquez Pérez, 2005, 306). La duración de todo este proceso post mortem es de cuarenta días ${ }^{23}$.

Los familiares y amigos recitan el Corán a pie de tumba durante las siete noches siguientes al entierro (Jover Maestre et alii, 2005, 24) o en el lugar en el que el muerto recibió la última plegaria (Longás Bartibás, $1990,300)^{24}$. Junto a las lecturas se realizan banquetes funerarios, de los que sí ha quedado constancia arqueológica en otros yacimientos peninsulares, con la presencia de candiles, jarras o restos de comida como pan y frutos (Márquez Pérez, 2005, 306-307). Finalmente, las visitas o ziyāra (Sourdel-Thomine, 1991, 367) a los cementerios no son de carácter obli-

21. En el Corán el término se recoge como ŷanna (Cortés, 1987) o también alchana (Longás Bartibás, 1990, 311).

22. Esta práctica fue reprobada por algunos alfaquíes (Fierro Bello, 2000, 181-183).

23. En los artículos acerca del ritual funerario islámico actuales señalan que el interrogatorio de la tumba dura siete días en el caso de los sinceros y piadosos y cuarenta si son impíos (www.webislam.com/idt=4066).

24. «Y, así les avezó este Pere Alonso a no entrar nadie estas siete noches en el aposento que murió ninguno, poniendo un escabel con unos manteles limpios y ençima una cuenca de agua para que se bañe el muerto, tuviendo lumbre toda la noche, y una alfombra limpia para que el muerto haga la çala. Y ençienden una candelita en cada esquina del aposento; y allí leyeron todos en arábigo, cada uno lo que sabía» (1990, 300-301, nota 2). gatorio ni quedan recogidas en fechas determinadas ${ }^{25}$, pero conllevan beneficios tanto para el difunto como para el que las realiza. La concepción de las maqābir peninsulares es más un centro de reunión, frecuentado por mujeres, hombres, niños, vendedores, cuentacuentos, decidores de futuro,... porque use cree que a la muerte le gusta encontrarse en medio del ruido y la actividad humana» (Burton-Page, 1991, 123).

\section{UN LUGAR DONDE VIVIR}

Este conjunto cementerial, necesariamente ha de estar vinculado a un núcleo de hábitat (Torres Balbás, 1983, 235 y ss.) por el momento no localizado en los alrededores del yacimiento, por lo que son tres las opciones más plausibles ${ }^{26}$ : la primera opción es que se trate de un asentamiento rural en llano, heredero de una uilla o pagus hispanovisigoda, que perviviría más allá del siglo VI y que a partir del VIII se pueden transformar en alquerías; la segunda posibilidad es que estemos directamente ante una alquería (qarya) de origen islámico, pues se localizaría en un nicho ecológico idóneo ${ }^{27} \mathrm{y}$, finalmente, la vinculación a un enclave urbano ya existente que sufriría una transformación de ciuitas a madinna. Cualquiera de las tres opciones de poblamiento serían válidas, mas al analizar el entorno próximo dentro de un marco cronológico situado entre los siglos V y X d. C., se observa una clara concentración de hallazgos en el área inmediata al yacimiento que no tiene parangón en el resto del término municipal de Alicante. Los hallazgos localizados en el casco urbano de la ciudad actual se centran en el barrio de Benalúa, donde queda patente la existencia de un centro artesanal y comercial, relacionado con el embarcadero natural de la playa del Baver y con cronologías que oscilan entre finales del siglo $\mathrm{V}$ y el VI (Reynolds, 1985, 148 y ss.; Sala Sellés y Ronda Femenía, 2000) fechas ampliadas hasta la primera mitad del siglo VII en un estudio reciente (Lara Vives et alii, 2007). En segundo lugar, estaría el hallazgo del Palacio Llorca, una necrópolis con veintisiete individuos que, aunque los materiales apuntan a una cronología más antigua (Gutiérrez Lloret, 1996, 241), ha sido datado entre los siglos VI y VII (Rosser Limiñana, 1994, 98); por último, los materiales que han proporcionado

25. Hay autores que señalan que se han de realizar los jueves por la tarde y los viernes por la mañana (Pozo Martínez, 1990, 115) o en grandes festividades (Pascua de Ramadán y Pascua de Carneros), colocando arrayanes sobre las tumbas (Casal García, 2003, 41-42; Dickie, 1985, 46).

26. Según los diferentes modelos de hábitat que se barajan para la zona de Sharq al-Andalus (Gutiérrez Lloret, 1996, 222 y ss. y 2007, 332 y ss.).

27. En la Vega Baja del Segura se localizan en laderas o elevaciones poco pronunciadas, normalmente coincidentes con la ocupación de áreas marginales por parte de poblaciones hispanorromanas (Gutiérrez Lloret, 1996, 284). 


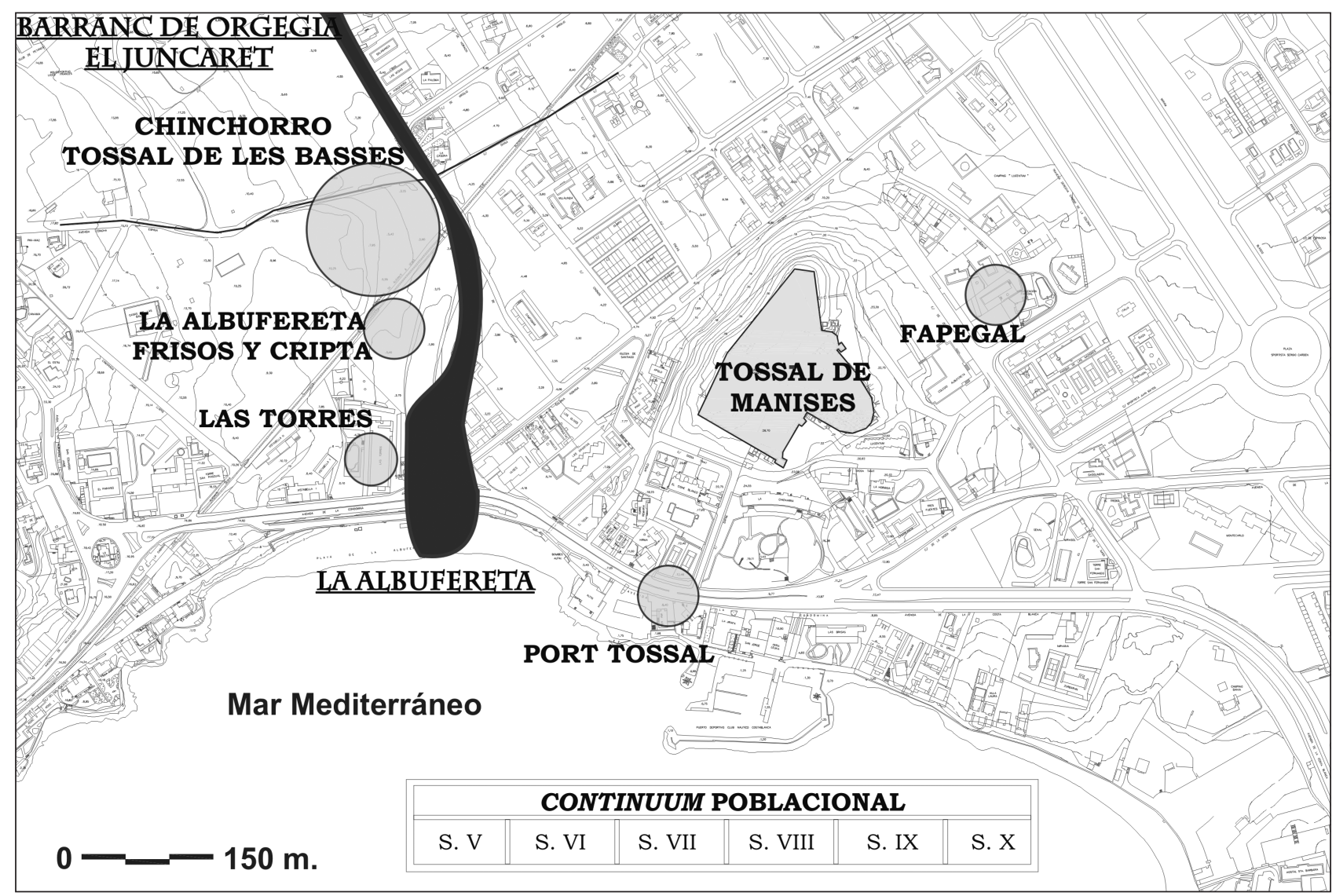

Figura 10: Plano de localización de los hallazgos en la zona de La Albufereta, que muestran la existencia de un continuum poblacional en el entorno durante los siglos $\mathrm{V}$ y X.

las prospecciones en el Monte del Benacantil (Reynolds, 1985, 246) con fechas del V al VII, un vertedero del siglo IX (Gutiérrez Lloret, 1998, 153; Rosser Limiñana, 1994, 97) y hallazgos monetarios en la zona de los siglos VIII y X (Doménech Belda, 2003, 236). Fuera del núcleo urbano, a 7 kilómetros al $\mathrm{O}$ de Alicante, a los pies de la Sierra de Fontcalent, se localiza un asentamiento de carácter rural, datado desde la segunda mitad del siglo VII a principios del VIII, en cuyas cercanías se halló un fals sin fecha ni ceca datado entre los siglos VIII y IX (Doménech Belda, 2003, 237; Gutiérrez Lloret, 1996, 371-373), pero donde no cristaliza la islamización.

Frente a éstas, los restos arqueológicos localizados en el área próxima a la ubicación de la maqbara del Tossal de Manises, nos marcan un continuum poblacional, ausente en el resto del término municipal (Fig. 10). Independientemente de la continuidad de hábitat de toda esta zona desde la Prehistoria, hecho que ya comentábamos al principio del artículo, es una cuestión especialmente evidente en el período que nos ocupa; desde la Tardoantigüedad hasta la implantación del modelo islámico. En el espacio de La Albufereta encontramos en este lapso temporal: la necrópolis de Port Tossal, fechada entre los siglos IV y V (Rosser Limiñana, 1994, 84-85); el área cementerial de Las
Torres, con alrededor de treinta tumbas de finales del siglo V y principios del VI (Rosser Limiñana, 1996); la necrópolis de El Chinchorro, que abarca un momento cronológico inmediatamente posterior, entre los siglos VI y VII, con al menos diez sepulturas (Rosser Limiñana, 1996, 19-20); el espacio funerario en el Camino de El Chinchorro, con centenares de sepulturas tardorromanas (siglos V al VII) y una veintena de ritual islámico, fechados por los autores en el mismo contexto que los hallados en el Tossal de Manises (Rosser Limiñana y Fuentes Mascarell, 2007, 72 y 78); un número indeterminado de sepulturas en la necrópolis del Fapegal, que P. Rosser Limiñana fecha en el siglo VII $(1994,95)$ y, por último, en el Tossal de les Basses, en cuyos alrededores se documentó una cámara de sillería a modo de cripta, de planta cuadrada de la que sólo se ha conservado su descripción, dada por Cayetano de Mergelina (Olcina Doménech y Pérez Jiménez, 2003, 115). En cuanto a puntos de hábitat relacionados con estos espacios funerarios, se continúa habitando el Tossal de les Basses (Rosser Limiñana y Fuentes Mascarell, 2007), donde se hallaron además dos losas talladas con simbología cristiana (Llobregat Conesa, 1970, 200-204). Sin lugar a dudas, este elevado conjunto arqueológico nos proporciona la imagen de que en los alrededores de La Albufereta 
se localizaría un núcleo de población de evidente desarrollo a partir del siglo VI y, sobre todo, en el VII, dado el alto número de enterramientos y la monumentalidad de los restos arquitectónicos ${ }^{28}$, datos que nos hacen plantear la hipótesis de la ubicación en la zona de la ciudad de Laqant, que aparece en el Pacto de Teodomiro. No sugeriríamos la existencia de una ciudad de tamaño considerable sino, probablemente, de un núcleo de hábitat de dudosa materialidad urbana, con una población en cierto modo relevante, dotada de una o varias construcciones de carácter notable y susceptible, por tanto, de aparecer como tal en el Pacto del año 713 (Tendero Porras, Guilabert Mas y Olcina Doménech, 2007, 191). Es cierto que no encontramos ninguna estructura urbana en el área de La Albufereta, por otro lado muy afectada por el fenómeno constructivo desde los años sesenta del siglo $\mathrm{XX}$, pero la acumulación de hallazgos entre los siglos $\mathrm{V}$ y X, hace que esta zona aparezca como una firme candidata para la localización de la ciudad de Laqant, protagonizando el momento de transición entre el mundo visigodo y el islámico, con el visible periclitar de las ciuitates visigodas en época emiral, fenómeno que desemboca, en época califal, en el surgimiento de las mudūn musulmanas. Es significativo, al respecto, que en aquellas ciudades que aparecen en el Pacto de Teodomiro, este acontecimiento implica un necesario desplazamiento geográfico, caso de Elche, Cehegín, Mula o Hellín, parangonable, sin duda, al ejemplo de Alicante. Para algunos de estos casos, como el de $I l \check{s}$, nadie duda de su emplazamiento en La Alcudia de Elche, heredera directa de la ciudad romana de Ilici y sede episcopal (siglos VI y VII), a pesar de no existir materiales o construcciones fechados en el VIII, pues no necesariamente ha de ser abandonada tras la conquista islámica (Gutiérrez Lloret, 2004, 108-109).

28. Las noticias acerca del hallazgo de la cripta indican que se trata del único edificio de sillería de fecha tardoantigua dentro de la provincia de Alicante, mientras que las losas señalan en la dirección de la presencia de un edificio de corte religioso, posiblemente una basílica (Tendero Porras, Guilabert Mas y Olcina Doménech, 2007, 190). En el estudio de una serie de piezas de escultura visigoda en el SE peninsular similares a las localizadas in situ en la basílica del Tolmo de Minateda, en Hellín (Albacete), se establecen paralelos con elementos aparecidos fuera de contexto en el Cerro de la Almagra en Mula (posiblemente la Müla del Pacto de Teodomiro), la placa de Begastri, un friso de Toledo y las aparecidas en La Albufereta, indicador de la existencia de un posible taller áulico (Gutiérrez Lloret y Sarabia Bautista, 2007, 313 y 331). Lo significativo de este hecho es que estos elementos arquitectónicos han sido localizados en núcleos urbanos visigodos y, todos ellos, salvo la capital del reino visigodo, están mencionados en el Pacto de Tudmīr del año 713, lo que pone de manifiesto la influencia de la población asentada en La Albufereta o, al menos, de una parte de ella.

\section{CONCLUSIÓN}

En definitiva, los datos arqueológicos muestran de forma clara el carácter basculante del poblamiento en la zona circundante al área de La Albufereta, entre el Tossal de Manises y el Tossal de les Basses, con un elevado número de hallazgos arqueológicos, y en concreto dentro del período que nos ocupa (desde los siglos $\mathrm{V}$ al $\mathrm{X}$ ), que así lo confirman. Recordemos que La Albufereta cuenta con la presencia de necrópolis tardorromanas y visigodas, la cripta, los relieves y la maqbara, todo ello en una fecha que engloba el Pacto de Teodomiro, por lo que resulta factible la existencia de la ciudad de Laqant en la zona, aunque será el devenir de las investigaciones futuras quienes arrojen más luz sobre este capítulo.

\author{
Manuel Olcina Doménech \\ Eva Tendero Porras \\ Antonio Guilabert Mas \\ MARQ, Alicante \\ Plaza Doctor Gómez Ulla s/n \\ 03013 Alicante \\ mholcina@dip-alicante.es \\ etendero@dip-alicante.es \\ aguilabert@dip-alicante.es \\ tossaldemanises@dip-alicante.es \\ www.marqalicante.com
}

\section{BIBLIOGRAFÍA}

Abad CASAl, L., Gutiérrez Lloret, S. y Gamo PARRAs, B., 2004: «El Tolmo de Minateda, Hellín (Albacete)», Investigaciones Arqueológicas en Castilla - La Mancha 1996-2002, 145-162, Salamanca.

ABD Al FATAH GARCíA, S. H., 2001: Usos funerarios islámicos: prontuario práctico de acuerdo con la tradición jurisprudencial de la escuela doctrinal y legal Ya'fari, edición digital.

AlBa CAlzAdO, M., 2005: «Dos áreas funerarias superpuestas, pagana e islámica, en la zona sur de Mérida», Mérida excavaciones arqueológicas, 2002, 8, 309-342.

AlCARAZ HernándEZ, F. M., 1990: «Excavación Arqueológica de Urgencia en la necrópolis hispano-musulmana de Puerta Purchena, Almería 1988», Anuario Arqueológico de Andalucía/1988, III, Actividades de Urgencia, 12-19.

Alcaraz Hernández, F. M. y SAn Martín Montilla, C., 1992: «Excavación arqueológica de urgencia en el paraje de la Era del Lugar, Mojácar, Almería 1990», Anuario Arqueológico de Andalucía/1990, III, Actividades de Urgencia, 30-32.

BAÑos SERRANO, J. y MARTÍNEZ LÓPEZ, J. A., 2004: «Aportación al estudio de la maqbara islámica de Alhama de Murcia: excavación en la calle Fulgencio Cerón Cava, $\mathrm{n}^{\circ}$ 2», Memorias de Arqueología, 13 (1998), 319-334, Murcia.

Baños Serrano, J., Ramírez Águila, J. A. y GonzÁlez GueraO, J. A., 2004: «Actuaciones arqueológicas en Alhama de Murcia, calle Corredera 16», en Resumen de 
las XV Jornadas de Patrimonio Histórico y Arqueología de la Región de Murcia, 100-102, Murcia.

Botella Ortega, D., DiÉguez Ramírez, J. P., Martínez ENAMORADO, V. y MORENA LÓPEZ, J. A., 2005: «Evidencias arqueológicas de un cementerio andalusí en Córdoba ila maqbara Umm Salama?», Boletín de Arqueología Medieval, 12, 19-50.

Burton-Page, J., 1991: «Makbara, V.- Inde», en C. E. Bosworth, B. Van Donzel, B. Lewis y Ch. Pellat, Encyclopédie de l'Islam, VI, 123-126, Leiden-París.

CARMONA ÁvilA, R. y LunA OSUNA, D., 1996: «La necrópolis y los arrabales hispanomusulmanes de La Cava: primeros resultados de una excavación arqueológica de urgencia en Madīnat Bāguh (Priego de Córdoba)», Antiquitas, 7, 115-134.

CARMONA Ávila, R. y LunA OsunA, D., 1999: «Nuevos datos sobre la configuración de Madīnat Bāguh (Priego de Córdoba): la necrópolis y los arrabales de la Cava», Anuario Arqueológico de Andalucía/1995, III, Actividades de Urgencia, 174-184.

CASAl GARCíA, M. T., 2001: «Los cementerios islámicos de Qurtuba», Anales de Arqueología Cordobesa, 12, 283-313.

CASAl García, M. T., 2003: Los cementerios musulmanes de Qurtuba, Arqueología Cordobesa, 9, Córdoba.

CHAPA BRUNET, M. T., 1991: «La arqueología de la muerte: planteamientos, problemas y resultados», en D. VAQUERIZO GIL (coord.), Arqueología de la muerte: metodología y perspectivas actuales, Córdoba, 13-38.

CORTÉS, J. (ed.), 1987: El Corán, edición, glosario y traducción de J. Cortés, Nueva York.

Curto Homedes, A., Loriente Pérez, A., Martínez LANDín, M. R. y Ros BARBOSA, E., 1986: «El cementiri musulmà del Castell de Suda de Tortosa (Tarragona)», Actas del I Congreso de Arqueología Medieval Española, Huesca, 1985, tomo III, Zaragoza, 655-665.

DiCKIE, J., 1985: «Dios y la Eternidad: mezquitas, madrasas y tumbas», en G. MicheLL (dir.), La arquitectura del mundo islámico, 15-47, Madrid.

DOMÉNECH BELDA, C., 2003: «Monedas e inscripciones tardorromanas e islámicas», en L. ABAD CASAL y J. M. ABASCAL PALAZÓN (coords.), Las ciudades y los campos de Alicante en época romana, Canelobre, 48, 223242, Alicante.

EsPinAR MOREnO, M. y QueSAdA GóMEZ, J. J., 2000: «Tipología de las tumbas musulmanas excavadas en el solar de la calle Agua de Cartuja número 8 (Granada)», en Estudios sobre Patrimonio, Cultura y Ciencias Medievales, II, 91-111, Cádiz.

FERNÁNDEZ DomíngueZ, C., 1995: «Último sondeo en el cementerio islámico de Málaga», en M. P. TORRES PALOMO y M. ACIÉn AlMANSA (eds.), Estudios sobre cementerios islámicos andalusies, 69-82, Málaga.

FERNÁNDEZ GUIRADO, I., 1995: «La necrópolis musulmana de Yābal Fāruh (Málaga)», en M. P. TORRES PALOMO y M. ACIÉn Almansa (eds.), Estudios sobre cementerios islámicos andalusíes, 37-68, Málaga.

FERNÁNDEZ Rodríguez, L. E., Cisneros García, M. I., Navarro Luengo, I., SuÁrez Padilla, J. y Salado
ESCAÑO, J. B., 2001: «Informe de la intervención arqueológica de urgencia en el Cerro del Almendro (Lomo del Espartal). Autopista de la Costa del Sol. Marbella (Málaga). 1997», Anuario Arqueológico de Andalucía/1998, III, Actividades de Urgencia, volumen 2, 613-624.

FIERRO BELlO, M., 2000: «El espacio de los muertos: fetuas andalusíes sobre tumbas y cementerios», en P. CRESSIER, M. FierRo y P. P. VAN StAFUel (eds.), Urbanismo musulmán, 153-189, Madrid.

Figueras PACHECO, F., 1971: Relación de hallazgos arqueológicos en el Tossal de Manises (Alicante) 19331935, Alicante.

Galve IzQuiERDO, P., 1995: «Necrópolis islámica de la Puerta de Toledo (Zaragoza): nuevas excavaciones», en M. P. TORRes PAlomo y M. Acién Almansa (eds.), Estudios sobre cementerios islámicos andalusies, 117-136, Málaga.

Galve IzQuierdo, P. y Benavente Serrano, J. A., 1992: «La necrópolis islámica de la Puerta de Toledo de Zaragoza», Actas del III Congreso de Arqueología Medieval Española (Oviedo, 1989), tomo II, 383-390, Oviedo.

Gómez Becerra, A. y Malpica Cuello, A., 1999: «Excavaciones de urgencia en el yacimiento de El Maraute (Motril, Granada). Campaña de 1995», Anuario Arqueológico de Andalucía/1995, III, Actividades de Urgencia, 191-199.

Guilabert Mas, A., Tendero Porras, E. y Olcina DoMÉNECH, M., 2007: «Las dataciones radiocarbónicas. Breves comentarios», en A. GUILABERT MAS ET ALII, La maqbara del Tossal de Manises (Alicante), tomo II: estudio antropológico, análisis sedimentológicos y óseos, resultados de las dataciones radiocarbónicas y musealización de la maqbara, M. OlcINA DOMÉNECH ET ALII, La maqbara del Tossal de Manises (Alicante), Serie Excavaciones Arqueológicas, Memorias no 4, 9197, Alicante.

GutiÉRrez Lloret, S., 1996: La cora de Tudmīr. De la Antigüedad Tardía al mundo islámico. Poblamiento y cultura material, Collection de la Casa de Velázquez, 57, Madrid-Alicante.

GUTIÉRREZ LlORET, S., 1998: «Ciudades y conquista. El fin de las ciuitates visigodas y la génesis de las mudun islámicas del sureste de al-Andalus», en P. CRESSIER y M. GARCÍA-ARENAL (eds.), Genèse de la ville islamique en al-Andalus et au Maghreb occidental (Granada 1995), 137-157, Madrid.

GutiÉRREZ LlORET, S., 2004: «Ilici en la Antigüedad Tardía», en Iberia, Hispania, Spania, 95-110, Alicante.

GUTIÉRREZ LlORET, S., 2007: «La islamización de Tudmīr: balance y perspectivas», en Ph. SÉNAC (ed.) Villa 2. Villes et campagnes de Tarracoinase et d'Al-Andalus (VI-XI siècles): la transition (Zaragoza, 2006), 323-367, Toulouse.

GutiÉRrez Lloret, S. y SARABiA BAUtista, J., 2007: «El problema de la escultura decorativa visigoda en el sudeste a la luz del Tolmo de Minateda (Albacete): distribución, tipologías funcionales y talleres», en L. Caballero Zoreda y P. Mateos Cruz (eds.), 
Escultura decorativa tardorromana y altomedieval en la Península Ibérica, Anejos del Archivo Español de Arqueología, XLI, 301-343, Madrid.

Haro NAVARro, M. y CARrión MéndeZ, F., 1999: «Informe sobre la excavación de urgencia en la necrópolis hispanomusulmana de Xarea, Vélez Rubio (Almería)», Anuario Arqueológico de Andalucía/1995, III, Actividades de Urgencia, 9-14.

Jover Maestre, F. J., López Seguí, E. y De Miguel IBÁÑEZ, M. P., 2005: «Bitrir: l'origen de Petrer», en F. J. Jover Maestre (coord.), Vida i mort a Petrer. Història dels cementeris, 18-31, Petrer.

Llobregat ConesA, E. A., 1970: «Materiales hispano-visigodos del Museo Arqueológico Provincial de Alicante», en Trabajos dedicados a D. Pío Beltrán, Papeles del Laboratorio de Arqueología de Valencia, 10, 189-204, Valencia.

LONGÁs BARTIBÁs, P., 1990 [1915]: Vida religiosa de los moriscos, Granada.

MÁRQUEZ PÉREZ, J., 2005: «Excavación de una de las áreas funerarias al sur de la ciudad: una maqbara al sur de Marida», Mérida excavaciones arqueológicas, Memoria 2002, 8, 281-308, Mérida.

Martínez García, J., Muñoz Martín, M. del M. y MeLLADO SÁEZ, C., 1990: «La secuencia estratigráfica de la excavación arqueológica de El Paso: del espacio funerario del siglo X-XI a la Almería nazarí», Coloquio Almería entre Culturas, 69-88, Almería.

MARTínez RoDRÍGUEZ, A., 2002: La religión en Lorca durante la Edad Media, Lorca.

MENCHÓN I BES, J., 1998: «Necrópolis altomedievales y despoblación en la provincia de Tarragona, el caso de la Conca Barberà», Arqueología y Territorio Medieval, $5,5-29$.

OlCINA DOMÉNECH, M. y PÉREZ JiMÉNEZ, R., 1998: La ciudad ibero-romana de Lucentum (El Tossal de Manises, Alicante). Introducción a la investigación del yacimiento arqueológico y su recuperación como espacio público, Alicante.

Olcina Doménech, M. y PÉRez JimÉnez, R., 2003: «Lucentum, la ciudad y su entorno», en L. ABAD CASAL y J. M. ABASCAL PALAZÓN (coords.), Las ciudades y los campos de Alicante en época romana, Canelobre, 48, 89-120, Alicante.

Pascual Pacheco, J. y Serrano Marcos, M. L., 1996: «Necrópolis islámicas en la ciudad de Valencia», Saitabi, 46, 231-252.

Peral Bejarano, C., 1995: «Excavaciones y estudio de los cementerios urbanos andalusíes. Estado de la cuestión», en M. P. Torres PAlomo y M. AcIÉn Almansa (eds.), Estudios sobre cementerios islámicos andalusies, 11-36, Málaga.

Ponce GARcía, J., 2002: «Los cementerios islámicos de Lorca. Aproximación al ritual funerario», Alberca, 1, 115-147.

Pozo MARTíneZ, I., 1990: «El ritual funerario de los cementerios islámicos de la Región de Murcia», en Guía islámica de la Región de Murcia, 113-121, Murcia.
Pozo MARTíneZ, I., 1992: «El cementerio islámico de la calle Polo de Medina (Murcia)», Actas del III Congreso de Arqueología Medieval Española (Oviedo, 1989), tomo II, 413-421, Oviedo.

Pozo Martínez, I. y Hernández CARrión, E., 2000: «El Conjunto arqueológico de la Rinconada de Olivares, Jumilla», Memorias de Arqueología, 9 (1994), 416-429, Murcia.

PUJANTE MARTíNEZ, A., 2004: «Excavación de urgencia solar calle Victorio - calle Mariano Vergara, Murcia. La evolución de dos viviendas medievales y de un sector del cementerio musulmán», Memorias de Arqueología, 13 (1998), 393-417, Murcia.

Ramírez Águila, J. A. y Urueña Gómez, M. I., 1998: «Aportaciones al estudio del poblamiento en Alhama de Murcia: excavaciones en calle Corredera, 5 y 7», Memorias de Arqueología, 7, 330-378, Murcia.

REYNODLS, P., 1985: «Cerámica tardorromana modelada a mano de carácter local, regional y de importación de la Provincia de Alicante», Lucentum, IV, 254-267.

Ríos Frutos, L. y PÉREZ AsENSIO, M., 2008: «Trauma peri mortem en la maqbara medieval de Baza, Granada», en C. Roca De Togores Muñoz y F. Rodes Lloret (eds.), Actas de las Jornadas de Antropología Física y Forense (Alicante, 29-30 de junio de 2006), 89-99, Alicante.

Rodes lloret, F., Chiarri Rodrigo, J., Cloquell RoDRIGO, B. y MARTÍ LLORET, J. B., 2000: Estudio de cuatro esqueletos humanos islámicos del Tossal de Manises (Alicante), Elche.

Roselló BORDOY, G., 1992: «Almacabras, ritos funerarios y organización social en Al-Andalus», Actas del III Congreso de Arqueología Medieval Española (Oviedo, 1989), tomo I, 151-16, Oviedo 8.

RosSER LIMIÑANA, P., 1994: «Nuevas aportaciones a la problemática de la Antigüedad Tardía en Alicante», Lqnt, 2, 69-110.

Rosser LimiñANA, P., 1996: «L'arqueologia de la mort en les excavacions del COPHIAM a Alacant», Quaderns de Migjorn, 2, 9-37.

Rosser Limiñana, P., Elayi, J. y Pérez Burgos, J. M., 2004: El Cerro de las Balsas y el Chinchorro: una aproximación a la arqueología del poblamiento prehistórico e ibérico de la Albufereta de Alicante, Alicante.

Rosser Limiñana, P. y Fuentes MASCARELl, C. (coords.), 2007: El Tossal de les Basses. Seis mil años de historia de Alicante, Alicante.

RuIZ MolinA, L., 2000a: «Hisn Yakka. Un castillo rural en Sarq Al-Andalus. Siglos XI al XIII. Excavaciones arqueológicas en el Cerro del Castillo de Yecla (19901999)», Revista de Estudios Yeclanos, Yakka, 10, Yecla.

Ruiz MolinA, L., 2000b: «V campaña de excavaciones arqueológicas en el Cerro del Castillo (Yecla, Murcia). Junio-septiembre de 1994», Memorias de Arqueología, 9 (1994), 388-399, Murcia.

SAla Sellés, F. y Ronda FemeníA, A., 2000: «El asentamiento tardorromano del barrio de Benalúa: las actuaciones arqueológicas de 1989», en Scripta in Honorem Enrique Llobregat, 443-458, Alicante. 
Serrano PeÑa, J. L. y Castillo Armenteros, J. C., 2000: «Las necrópolis de Marroquíes Bajos (Jaén). Avance de las investigaciones arqueológicas», Arqueología y Territorio Medieval, 7, 93-120.

Seva Román, R., LANDETE Ruiz, M. D. y Vidal BERnABEU, G., 2007: «Análisis sedimentológicos y óseos», en A. GuILABert MAs et alii, La maqbara del Tossal de Manises (Alicante), tomo II: estudio antropológico, análisis sedimentológicos y óseos, resultados de las dataciones radiocarbónicas y musealización de la maqbara, M. OlCINA DOMÉNECH et alii, La maqbara del Tossal de Manises (Alicante), Serie Excavaciones Arqueológicas, Memorias n 4, 71-89, Alicante.

Sourdel-Thomine, J., 1991: «Kabr», en C. E. Bosworth, B. VAN Donzel, B. Lewis y Ch. Pellat, Encyclopédie de l'Islam, VI, 367-370, Leiden-París.

Tendero Porras, E., Guilabert Mas, A. y Olcina DoMÉNECH, M., 2007: La maqbara del Tossal de Manises (Alicante), tomo I: estudio arqueológico, en M. OLCINA DOMÉNECH et alii, La maqbara del Tossal de Ma- nises (Alicante), Serie Excavaciones Arqueológicas, Memorias $n^{\circ} 4$, Alicante.

TOMASSETti GuerRA, J. M., JimÉNEZ-CAMINO ÁlVAREZ, R., FERNÁNDEZ GALlEGO, C., BRAVO JiMÉNEZ, S., NAVARRO Luengo, I. y SuÁrez PAdilla, J., 2005: «El cementerio islámico del Fuerte de Santiago (Algeciras, Cádiz). Nuevas excavaciones y síntesis interpretativa», Boletín de Arqueología Yaziri. Ias Jornadas de Arqueología del Campo de Gibraltar. Protección de Patrimonio, Tarifa 23-25 de abril de 2004, Algeciras, Edición digital, 96-112, Algeciras.

TORRES BALBÁs, L., 1983: «Cementerios hispanomusulmanes», en Crónica de la España musulmana, 6. Obra dispersa I. Al-Andalus, Instituto de España, 144-191, Madrid.

Verdú PARRA, E., 2005: Francisco Figueras Pacheco y las excavaciones en la necrópolis ibérica de La Albufereta de Alicante (1934-1936), Alicante.

Enlaces de interés en Internet: www.islamerica.org.ar/dofune1.html www.webislam.com 